\title{
Molecular monitoring of the therapeutic effect of Albendazole on Ascaris lumbricoides and Ancylostoma duodenale infected children using conventional multiplex PCR
}

\author{
Samah H Yahia, Howayda SF Moawad, Tahani I Farag, Samira M Mohammad \\ Department of Medical Parasitology, Faculty of Medicine, Zagazig University, Egypt
}

\begin{abstract}
Background: Globally, many individuals are infected with soil-transmitted helminths (STHs) with majority occurring in tropical and subtropical regions of the world. Albendazole (ADZ) is a broad-spectrum anthelmintic used efficiently for STHs control. Upgrading the assessment of ADZ efficacy is important to confirm that drug resistance has not emerged.

Objective: To assess the therapeutic efficacy of ADZ in both A. lumbricoides and A. duodenale infections by conventional multiplex PCR.

Subjects and Methods: Stool specimens from 191 boys and 123 girls, aged from 2 to 13 years were screened by saline wet mount and iodine stained smears and cellophane thick smears (Kato-Katz technique). All positive cases were given a single oral dose of $400 \mathrm{mg} \mathrm{ADZ}$ then 2 weeks later new stool samples were collected and subjected to multiplex PCR. Before medication, anemia assessment (finger prick capillary blood sample) was performed.

Results: Prevalence of infection with A. lumbricoides and A. duodenale was $20.7 \%$ and $5.4 \%$, respectively. Parasitic infections were more prevalent in age group 7-13 years (59\%) than in 2-6 years (41\%) respectively. Boys were slightly more affected than girls (52.6\% versus $47.4 \%)$. Prevalence of parasitic infections among cases living in rural areas proved to be higher than those living in urban areas (65.4\% versus $34.6 \%)$. Examination for associated anemia showed that $35.9 \%$ of infected cases were anemic ( $\mathrm{Hb}$ level $<11.5 \mathrm{mg} / \mathrm{dl}$ ) versus $9.7 \%$ in non-infected cases. Diarrhea and colic were more prevalent in infected cases (39.7\% and $62.8 \%$, respectively) than in those that were non-infected (5.5\% and $8.9 \%$, respectively). The therapeutic efficacy of ADZ resulted in a cure rate of $93.8 \%$ and $88.2 \%$ for A. lumbricoides and A. duodenale infections, respectively; with an egg reduction rate (ERR) of $96.1 \%$ and $91.2 \%$, respectively. The multiplex PCR sensitivity was $100 \%$ for detection of both worms; the specificity was $96.8 \%$ and $93.8 \%$, respectively, with diagnostic accuracy of $96.9 \%$ and $94.1 \%$, respectively.

Conclusion: Multiplex PCR was useful for measurement of the therapeutic efficacy of ADZ as an anthelminthic drug.
\end{abstract}

Keywords: Albendazole, A. duodenale, A. lumbricoides, multiplex PCR, prevalence.

Received: 6 March, 2019, Accepted: 8 April, 2019.

Corresponding Author: Howayda SF Moawad, Tel.: 00201126576573, E-mail: drhowaydasaid@gmail.com

Print ISSN: 1687-7942, Online ISSN: 2090-2646, Vol. 12, No. 1, April, 2019.

\section{INTRODUCTION}

Soil-transmitted helminths (geohelminths) belong to the group of neglected tropical diseases. This assembly of infectious diseases include parasites namely $A$. lumbricoides, T. trichiura, and the two hookworm species, A. duodenale and N. americanus causing an extensive variety of clinical symptoms and signs. S. stercoralis is one of the most important and often neglected additional STH affecting $10-40 \%$ of the population mainly in sub-Saharan Africa and Southeast Asia ${ }^{[1]}$. Geohelminths can affect human health either directly by damaging the internal mucosa of the gut and feeding on host's blood and serum, or indirectly through production of inflammatory cytokines that affect appetite and food intake of hosts especially children $^{[2]}$. Both mechanisms are a dual burden of parasitic infection leading to malabsorption with drastic deficiencies in macro and micronutrients which in turn leads to a malnutrition state that increases susceptibility to infection by inducing alterations in host immune function. These factors not only affect the physical development of children, but also they impair their cognitive development leading to retarded academic performance ${ }^{[3]}$.

Geohelminths are transmitted by a fecal-oral route, which explains its high rate of prevalence in areas deprived of proper socioeconomic development and/or lack of proper sanitary environmental health conditions; criteria known to be present in low and middle income countries, including Egypt ${ }^{[4]}$. In developing countries, these worms continue to represent an actual health problem infecting millions of people and exhausting its health budget annually. Globally, the infection with at least one species of geohelminths occurred in more than a billion patients. Most of them are those living in low income countries deprived of education, health 
sanitary conditions and complaining of malnutrition ${ }^{[5]}$. The majority are also likely to be chronically infected by more than one species of these worms ${ }^{[6]}$. These children are not only natural victims of geohelminths infection due to their immature immune systems, but they also represent a major source of infection in these communities due to their uncontrolled fecal handmouth activities ${ }^{[7,8]}$.

The traditional method for the diagnosis of STHs infections is microscopic examination, using either direct fecal smear or various fecal concentration methods, which are time-consuming, and insensitive. For example, although the Kato-Katz technique increases the detection rates of some helminth species and provides quantitative results, the diagnosis of hookworm is difficult due to the rapid disintegration of the eggs. Also, differentiation between hookworm species is difficult, and the detection of Strongyloides stercoralis larvae is poor ${ }^{[9]}$. The use of conventional and real-time PCR can overcome these diagnostic limitations as they have proved to be highly sensitive and specific for detection of many intestinal parasites ${ }^{[10]}$. In addition, quantitative multiplex PCR shows high sensitivity and specificity, but the high cost and need for special instruments still present obstacles limiting their applications in parasitological routine diagnosis. Therefore, a conventional multiplex PCR assay that has lower cost and greater simplicity, was developed, for the simultaneous detection of STHs in stool samples ${ }^{[11]}$.

Since WHO declaration of its strategy in 2001 to control neglected tropical diseases, including geohelminths, combating these infections became the major concern of many countries including Egyp $\mathrm{t}^{[12]}$, with the aim of maintaining the individual worm burden below morbidity and mortality levels. In cooperation with WHO and the international health bodies, these countries work hard to implement an integrated plan for improving the quality of the environment by providing clean water supplies, intensifying health education, and economic development in line with mass chemotherapy campaigns as recommended by WHO in a trial to combat these parasites ${ }^{[13,14]}$. The control of geohelminths infections is particularly challenging because of the high rate of reinfection, particularly in environments where control depends mainly on environmental health sanitation and development which are expensive and need a long time to be implemented representing a real challenge for countries with limited income ${ }^{[15]}$. Accordingly, WHO adopted worldwide national mass treatment campaigns based on large-scale deworming programs incorporation with international pharmaceutical bodies $^{[16]}$

Because numbers of infections may sometimes be underestimated, WHO adopted the strategy of giving safe, single-dose, affordable drugs to all at high risk groups at regular intervals. Albendazole (a benzimidazole derivative) is an effective broadspectrum anthelmintic drug against a wide range of helminths. This drug is the mainstay of the control chemotherapy strategy adopted by the WHO provided as a single-dose of $400 \mathrm{mg}$ given randomly to all high risk groups in endemic areas over the age of 2 years. It recommends periodic mass drug administration of ADZ to school children ${ }^{[13]}$. Although the treatment proved to be highly effective against geohelminths ${ }^{[14]}$, evidence regarding its effective therapeutic action, even in repeated doses, has been questioned and needs continuous evaluation ${ }^{[17]}$. Moreover, a major concern is the parasitic resistance to $\mathrm{ADZ}$ which represents an adverse impact on the effectiveness and sustainability of chemotherapeutic campaigns to disease transmission and control, leading to its failure ${ }^{[18]}$. Due to the wide use of anthelminthic drugs globally and the rapid development of resistant parasite strains, ADZ remains a priority for researchers to continuously evaluate and investigate its efficacy ${ }^{[19,20]}$.

The aim of this study is to monitor the effect of ADZ drug on $A$. duodenale and A. lumbricoides using conventional multiplex PCR technique as prerequisite for a successful control strategy. Also, the study aims to provide reliable data for the governmental health authorities for decision making regarding the effectiveness of the chemotherapeutic campaigns; whether to continue or shift to another medication.

\section{SUBJECTS AND METHODS}

This cross-sectional analytical study was performed on children attending Gastroenterology Unit in Zagazig University Pediatrics Hospital from December 2017 to October 2018. The study was conducted at the Medical Parasitology Department, Faculty of Medicine, Zagazig University.

Subjects: The study was carried out on 314 cases (191 boys and 123 girls); ages ranging from 2 years to 13 years. They complained of different abdominal symptoms as abdominal pain, diarrhea, loss of appetite and weight loss with or without pallor. Children or their parents were asked about socio-behavioral data (i.e. occupation, parent's education, wearing shoes, personal hygiene, food consumption and sources of drinking water). At enrollment, a full clinical examination was conducted, including measurement of weight, height, temperature, anemia and relevant medical history. Children were excluded from the study if they had recent history of anthelmintic treatment or reported hypersensitivity to ADZ.

Samples collection and parasitological procedures: All collected stool samples were examined within $4 \mathrm{~h}$ after collection. For each pre- and post-medication specimen, saline wet mount and iodine stained smears $^{[21]}$, and Kato-Katz technique smears ${ }^{[9]}$ were 
prepared on microscope slides using standard $50 \mathrm{mg}$ templates. Kato-Katz thick smears were quantitatively examined under a light microscope using $100 \mathrm{x}$ magnification. The number of eggs in one gram of feces was calculated by multiplying the obtained value by 20. It is used as a baseline data for the cure rate and ERR estimation, also to grade the infection as light, moderate, and heavy, according to WHO guidelines for STHs. Infection intensity classifications were as follows: light $A$. lumbricoides 1-4999 eggs/gram stool (EPG), moderate 5000-49999 EPG and heavy $\geq 50000$ EPG[22]; A. duodenale, light 1-1999 EPG, moderate 2000-3999 EPG, and heavy $\geq 4000 \mathrm{EPG}^{[23]}$.

Determination of hemoglobin $(\mathrm{Hb})$ levels: Before ADZ administration, anemia was monitored using finger prick capillary blood sample. Child was considered anemic if the $\mathrm{Hb}$ level was below $11.5 \mathrm{mg} / \mathrm{dl}^{[23]}$.

Drugs administration: ADZ (Alzental, EIPICO, Egypt, $20 \mathrm{mg} / \mathrm{ml}$ ) $400 \mathrm{mg}$ single oral dose was given for all infected children on an empty stomach. They were asked to come back to the hospital $2 \mathrm{w}$ after administration of medication to repeat stool examination and assess the efficacy of treatment. ERR was calculated using the following formula ${ }^{[24]}$ : ERR $=$ [(Mean EPG pre-treatment - Mean EPG post-treatment)/Mean EPG pre-treatment] $X$ 100. Cure rate was calculated using the following formula ${ }^{[24]}$ : Cure rate $=$ (No. of positive cases pretreatment who become negative post-treatment/No. of positive cases pre-treatment) X 100.

DNA extraction: Post medication stool samples preserved at $-20^{\circ} \mathrm{C}$ were defrosted at room temperature. The DNA was extracted from stool samples using the QIAamp Mini kit (Qiagen, Hilden, Germany) according to the manufacturer's instructions with minor modifications. About $100 \mathrm{mg}$ of stool were suspended in $200 \mu \mathrm{L}$ of phosphate buffered saline (PBS) that contain 2\% polyvinylpolypyrolidone (PVPP; Sigma, Steinheim, Germany); then heated for $10 \mathrm{~min}$ at $100^{\circ} \mathrm{C}$. ATL buffer containing proteinase $\mathrm{K}$ was added to the suspension then left for $3 \mathrm{~h}$ at $55^{\circ} \mathrm{C}$ before performing the DNA extraction. Phocine herpes virus 1 (PhHV-1) $103 \mathrm{PFU} / \mathrm{ml}$ was added to the AL lysis buffer to serve as the internal positive control for the extraction process. The extracted DNA samples were stored at $-20^{\circ} \mathrm{C}$ until amplified and analyzed ${ }^{[25]}$.
Multiplex PCR amplification: Specific primers to detect $A$. duodenale and $A$. lumbricoides in stool samples are shown in table (1).

A $50 \mu$ volume was prepared from 2X KAPATaq Ready Mix DNA polymerase (1.25 U KAPATaq DNA polymerase, $0.4 \mathrm{mM} \mathrm{dNTP}$, and reaction buffer with $\mathrm{Mg}^{2+}$ ), plus $20 \mathrm{pmol}$ of Ascaris and Ancylostoma specific primers, $1 \mu \mathrm{l}$ of DNA template, and sterile distilled $\mathrm{H} 2 \mathrm{O}$. PCR thermocycling (C1000TM Thermal Cycler BIORAD, Hercules, CA) was performed as follows: $95^{\circ} \mathrm{C}$ for $3 \mathrm{~min}$ then 35 cycles of $95^{\circ} \mathrm{C}$ for $30 \mathrm{sec}$ then $53^{\circ} \mathrm{C}$ for 30 sec and $72^{\circ} \mathrm{C}$ for $1 \mathrm{~min}$; lastly a final step of $72^{\circ} \mathrm{C}$ for 5 min. The amplified DNA samples were analyzed using $2 \%$ agarose gel electrophoresis at 50 volts for $1 \mathrm{~h}$, and then visualized using ethidium bromide and recorded via gel documentation system (G:Box HR; Syngene, Cambridge, UK) ${ }^{(11)}$.

Statistical analysis: Statistical analysis was done via the statistical package SPSS version 17 (Chicago, IL, USA). Pre- and post-treatment prevalence were compared using Chi-square test. Anthropometric measures of children were calculated as mean \pm SD. Statistical significance was set at $P<0.05$. Evaluation of multiplex PCR was based on the sensitivity, specificity, positive and negative predictive values and diagnostic accuracy.

Ethical consideration: Ethical approval was obtained from the Committee of Research, Publications and Ethics of the College of Medicine, Zagazig University, Egypt. All procedures were explained to patient's parents and a written or thumb-printed informed consent was obtained.

\section{RESULTS}

Stool examination revealed parasitic infection in $78 / 314(24.8 \%)$ samples, 74 of which showed a single parasitic infection with $A$. lumbricoides or $A$. duodenale and 4 showed mixed infection with both. Prevalence of $A$. lumbricoides infection was $20.7 \%$ and that of $A$. duodenale infection was $5.4 \%$. Among the 65 A. lumbricoides infected cases, $57(87.7 \%)$ had light infection, $7(10.8 \%)$ had moderate infection and only one $(1.5 \%)$ had heavy infection. Among the $17 \mathrm{~A}$.

Table 1. Specific primers.

\begin{tabular}{|c|c|c|}
\hline Primers & Company & Notes \\
\hline $\begin{array}{l}\text { A. duodenale (GenBank accession AJ001594) } \\
\text { Forward 5'- GAA TGA CAG CAA ACT CGT TGT TG -3' } \\
\text { Reverse 5'-ATA CTA GCC ACT GCC GAA ACG T-3' }\end{array}$ & $\begin{array}{l}\text { Biolegio, Malden, The } \\
\text { Netherlands }\end{array}$ & $\begin{array}{l}\text { Used to amplify a } 71 \text {-bp fragment of the Internal } \\
\text { transcribed spacer } 2 \text { (ITS2) sequence }{ }^{[10]} \text {. }\end{array}$ \\
\hline $\begin{array}{l}\text { A. lumbricoides (GenBank accession EU582499) } \\
\text { Forward 5'- GGA GGT TTT TGG GTC TTT GG -3' } \\
\text { Reverse5'- CCA AAC AAG GTA GCC AAC CA -3' }\end{array}$ & $\begin{array}{l}\text { Applied Biosystems, } \\
\text { Foster City, CA, USA }\end{array}$ & $\begin{array}{l}\text { Used to amplify 192-bp fragment of the DNA } \\
\text { regions of }(\mathrm{COI})^{[11]} \text {. }\end{array}$ \\
\hline $\begin{array}{l}\text { Phocine herpes virus (GenBank accession 24) } \\
\text { Forward 5'-GGG CGA ATC ACA GAT TGA ATC-3' } \\
\text { Reverse 5'-GCG GTT CCA AAC GTA CCA A-3' }\end{array}$ & $\begin{array}{l}\text { Biolegio, Malden, The } \\
\text { Netherlands }\end{array}$ & $\begin{array}{l}\text { Used as an internal positive control for the } \\
\text { extraction process }{ }^{[26]} \text {. }\end{array}$ \\
\hline
\end{tabular}


duodenale infected cases, 14 (82.4\%) had light infection and $3(17.6 \%)$ had moderate infection (Table 2).

Parasitic infections were more prevalent in 7-13 years age group (59\%) than in that of 2-6 years $(41 \%)$ with a significant statistical difference $(P=0.028)$. Boys $(52.6 \%)$ were slightly more affected than girls (47.4\%) without statistical significant difference. Prevalence of parasitic infection among cases living in rural areas $(65.4 \%)$ was higher than in those living in urban areas $(34.6 \%)$ with a statistically significant difference $(P=$ 0.007) (Table 3).

The recorded mean weight $(24 \pm 1.8 \mathrm{~kg})$ and height $(129 \pm 12.7 \mathrm{~cm})$ of infected group was statistically insignificant; and in non-infected group they were $27 \pm 2.3 \mathrm{~kg}$ and $131 \pm 10.2 \mathrm{~cm}$, respectively. Statistically significant anemia was recorded in $35.9 \%$ of infected cases versus $9.7 \%$ of non-infected cases $(P=0.000)$. Diarrhea was documented in $39.7 \%$ of infected cases and $5.5 \%$ of non-infected cases with significant statistical difference $(P=0.000)$. Colic complaint in $62.8 \%$ infected cases was statistically significant than in $8.9 \%$ of non-infected cases. (Table 4 ).

Evaluation of the therapeutic efficacy of ADZ showed that the cure rates for $A$. lumbricoides and $A$. duodenale were 93.8\% (95\% CI: 91.14-96.46\%) and 88.2\% (95\% CI: 84.64-91.76\%), respectively. The ERR for A. lumbricoides and A. duodenale were 96.1\% (95\% CI: 93.96- 98.24\%) and 91.2\% (95\% CI: 88.07-94.33\%), respectively (Table 5). Multiplex PCR detected 2 post treatment cases of $A$. lumbricoides (192 bp) and one case of $A$. duodenale $(71 \mathrm{bp})$ which were negative by microscopy. Multiplex PCR sensitivity was $100 \%$ in detection of both worms with a specificity of $96.8 \%$ for $A$. lumbricoides and $93.8 \%$ for $A$. duodenale, with diagnostic accuracy $96.9 \%$ for $A$. lumbricoides and 94.1\% for A. duodenale (Figure 1).

Table 2. Frequency and intensity of A. lumbricoides and A. duodenale among infected children.

\begin{tabular}{lcccccc}
\hline \hline & \multicolumn{3}{c}{ No. (\%) } & \multirow{2}{*}{ Total } \\
\cline { 2 - 5 } & Light & Moderate & Heavy & Single & Mixed & $65(20.7 \%)$ \\
\hline A. lumbricoides & $57(87.7)$ & $7(10.8)$ & $1(1.5)$ & 61 & 4 & $17(5.4 \%)$ \\
A. duodenale & $14(82.4)$ & $3(17.6)$ & $0(0)$ & 13 & 4 & $17 \%$ \\
\hline \hline
\end{tabular}

Table 3. Demographic data of infected children

\begin{tabular}{lcccc}
\hline \hline & \multicolumn{2}{c}{ Infected cases } & \multicolumn{2}{c}{ Statistical analysis } \\
\cline { 2 - 5 } & No. & \% & Chi-squares $\left(\boldsymbol{X}^{2}\right)$ & P value \\
\hline 2-6 years & 32 & 41 & 4.84 & $0.028^{*}$ \\
7-13 years & 46 & 59 & & 0.085 \\
Boys & 41 & 52.6 & 2.97 & $0.007^{*}$ \\
Girls & 37 & 47.4 & & 7.23 \\
Rural & 51 & 65.4 & & \\
Urban & 27 & 34.6 & & \\
\hline Total & $\mathbf{7 8}$ & $\mathbf{2 4 . 8}$ &
\end{tabular}

*Significant differences at $P$ value $<0.05$.

Table 4. Anthropometric measures and clinical problems of examined groups.

\begin{tabular}{|c|c|c|c|c|}
\hline & Infected & Non infected & Statistical analysis & $P$ value \\
\hline Weight $(\mathrm{Kg})($ Mean \pm SD) & $24 \pm 1.8$ & $27 \pm 2.3$ & $t$ test $=0.78$ & 0.227 \\
\hline Height $(\mathrm{cm})($ Mean \pm SD) & $129 \pm 12.7$ & $131 \pm 10.2$ & $t$ test $=0.92$ & 0.188 \\
\hline \multicolumn{5}{|l|}{ Anemia no. (\%) } \\
\hline Positive & $28(35.9)$ & $23(9.7)$ & $X^{2}=29.5$ & $0.000 *$ \\
\hline Negative & $50(64.1)$ & $213(90.3)$ & & \\
\hline \multicolumn{5}{|l|}{ Diarrhea, no. (\%) } \\
\hline Positive & $31(39.7)$ & $13(5.5)$ & $X^{2}=57.02$ & $0.000 *$ \\
\hline Negative & $47(60.3)$ & $223(94.5)$ & & \\
\hline \multicolumn{5}{|l|}{ Colic, no. (\%) } \\
\hline Positive & $49(62.8)$ & $21(8.9)$ & $X^{2}=98.4$ & $0.000 *$ \\
\hline Negative & $29(37.2)$ & $215(91.1)$ & & \\
\hline
\end{tabular}




\begin{tabular}{|c|c|c|}
\hline & A. lumbricoides & A. duodenale \\
\hline \multicolumn{3}{|l|}{ Mean egg count/gm stool } \\
\hline Pre treatment & 4173 & 982 \\
\hline Post treatment & 163 & 86 \\
\hline ERR\% (95\% CI) & $96.1(93.96-98.24)$ & $91.2(88.07-94.33)$ \\
\hline \multicolumn{3}{|l|}{ No. of infected cases } \\
\hline Pre treatment & 65 & 17 \\
\hline Post treatment by microscopy & 2 & 1 \\
\hline Post treatment by multiplex PCR & 4 & 2 \\
\hline Cure rate\% $(95 \% \mathrm{CI})$ & $93.8(91.14-96.46)$ & $88.2(84.64-91.76)$ \\
\hline \multicolumn{3}{|l|}{ Multiplex PCR } \\
\hline Sensitivity & $100 \%$ & $100 \%$ \\
\hline Specificity & $96.8 \%$ & $93.8 \%$ \\
\hline PPV & $50 \%$ & $50 \%$ \\
\hline NPV & $100 \%$ & $100 \%$ \\
\hline Diagnostic accuracy & $96.9 \%$ & $94.1 \%$ \\
\hline
\end{tabular}

ERR: Egg reduction rate, 95\% CI: (95\% confidence interval), PPV: Positive predictive value, NPV: Negative predictive value.

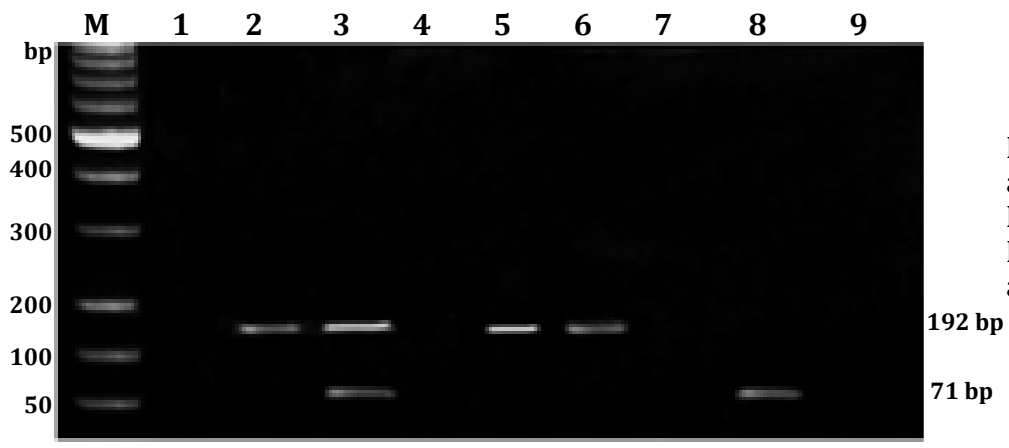

Fig. 1. Gel electrophoresis analysis of multiplex PCRamplified A. lumbricoides and A. duodenale DNA. M: Molecular weight DNA ladder.

Lanes 1- 9 represent parasites DNA bands at $192 \mathrm{bp}$ and $71 \mathrm{bp}$, respectively in stool samples.

\section{DISCUSSION}

Parasitic infections mainly STHs remain a major public health problem in developing countries. Regular deworming with anthelmintic drugs mainly ADZ and mebendazole is the current global control strategy ${ }^{[23]}$. Our study aimed to assess the therapeutic efficacy of a single oral dose of $400 \mathrm{mg}$ ADZ on both A. lumbricoides and $A$. duodenale infections by conventional multiplex PCR.

Concerning the prevalence and intensity of parasitic infections according to area, age and sex, controversial recorded differences could be generally attributed to the geographical distribution of the patients and conditions of exposure to infection. In our study the prevalence of parasitic infection was $24.8 \%(78 / 314)$. Prevalence of $A$. lumbricoides infection was $20.7 \%$ while, that of $A$. duodenale was $5.4 \%$ (Table 2). These results are a higher record than that reported in 2015 by Abd Ella et al., ${ }^{[27]}$ who reported a prevalence of $6.64 \%$ and $1.75 \%$ respectively in Qena province in Egypt. Also, Vaz Nery et al., ${ }^{[24]}$ reported $2.6 \%$ prevalence of Ancylostoma spp. in Timor-Leste Susana. Exceeding our results for A. lumricoides Krücken et al., ${ }^{[28]}$ reported a pre-ADZ treatment prevalence of $33.3 \%$ for Ascaris in Rwandan schoolchildren, and Augusto et al., ${ }^{[29]}$ detected $65.8 \%$ rate in children and young adults in Mozambique.
Among the 65 A. lumbricoides infected cases, 87.7\% had light infection, $10.8 \%$ had moderate infection and only $1.5 \%$ had heavy infection; while among the 17 A. duodenale infected cases, there were only light infections $(82.4 \%)$ and moderate $(17.6 \%)$ infections (Table 2). Similarly, Soukhathammavong et al., ${ }^{[23]}$ who tested both ADZ and mebendazole effect on hook worms and Ascaris infection, reported that most of the cases had light infection, few had moderate infection and heavy infection was rare. Also, Smith et al., ${ }^{[30]}$ in their study found that overall infections of Ascaris were mostly moderate and light.

According to age, we recorded a significant statistical prevalence of parasitic infections in age group 7-13 years (59\%) than 2-6 years (41\%). Hegazy et al., ${ }^{[31]}$ had reported an apparently higher prevalence of $51.8 \%$ in children aged between 2-6 years in Damanhur province, Egypt; while El-Masry et al., ${ }^{[32]}$ detected $60.2 \%$ rate among Egyptian school children in Sohag governorate villages. Controversially, Ibrahium $^{[33]}$ found that the prevalence among Egyptian school children in a village in El-Minia governorate was $29.3 \%$. Regarding sex, boys (52.6\%) appeared to be insignificantly more affected than girls (47.4\%). In agreement Abd Ella et al., ${ }^{[27]}$ found parasitic infection more common in males $49.5 \%$ than females $40.25 \%$. 
Also, Dyab et al., ${ }^{[34]}$ reported that parasitic infection was more prevalent in boys $53.8 \%$ than girls $46.2 \%$.

Correlation of mean weights of $24 \pm 1.8 \mathrm{~kg}$ in infected group with $27 \pm 2.3 \mathrm{~kg}$ in non-infected group was statistically insignificant. Also, the difference between mean heights of infected and non-infected groups $(129 \pm 12.7 \mathrm{~cm}$ and $131 \pm 10.2 \mathrm{~cm}$, respectively) was insignificant. Similarly Soukhathammavong et al., ${ }^{[23]}$ found that the mean weight of infected group taking both ADZ and mebendazole for treating $A$. duodenale and $A$. lumbricoides was $24.0 \pm 6.0$ and $25.2 \pm$ 6.0 respectively, and mean height was $124.1 \pm 11.0$ and $127.0 \pm 11.0$, respectively.

As expected results of prevalence of parasitic infections according to residence, was statistically greater among cases living in rural areas (65.4\%) than those living in urban areas (34.6\%). Likewise Dyab et al., ${ }^{[34]}$ and Abd Ella et al., ${ }^{[27]}$ reported higher rates of parasitic infection in rural than urban areas $(60 \%$ and $40 \%)$ and (50.95\% and $38.35 \%)$, respectively. Esrey et al., ${ }^{[35]}$ suggested that poor sanitation and usage of feces as fertilizers are the main contributing factors for elevated risk of parasitic infection in rural communities.

Consequently, children living in rural areas of developing countries have increased risk of anemia, poor growth and STHs infections. These are usually strongly associated with long-term nutritional stress manifested clinically as anemia, retarded growth, and cognitive impairment ${ }^{[36]}$. Regarding anemia, in our work, the recorded $\mathrm{Hb}$ levels were significantly lower $(35.9 \%)$ in infected cases than in non-infected ones $(9.7 \%)$. Crompton and Nesheim ${ }^{[37]}$ and $\mathrm{WHO}^{[38]}$ established that parasitic infections as ascariasis are usually associated with anemia as a sequel of inflammation and malnutrition.

Because of these worm infections gastrointestinal manifestations as diarrhea and colic were the main symptoms. Diarrhea and colic were respectively more significantly prevalent in infected patients $339.7 \%$ and $62.8 \%$ ) than non-infected ones (5.5\% and $8.9 \%$ ). These results coincide with the report by Dyab et al.,[34] who found significant increase of diarrhea, recurrent abdominal pain and pallor in infected students when compared to those who were non-infected. A similar result was also reported by Khadka et al., ${ }^{[39]}$ who detected increased prevalence of intestinal parasitosis among school children with abdominal discomfort, pain and diarrhea.

ADZ is widely used drug in preventive chemotherapy programs targeting STHs infections worldwide ${ }^{[40]}$. Its wormicidal activity is mainly through binding to intracellular microtubules and preventing their elongation. This leads to inhibition of absorption of molecules that are critical for parasite growth. This action affects the parasites rather than the host ${ }^{[41]}$.
In our study, the cure rate by ADZ was substantial for A. lumbricoides recording 93.8\% (95\% CI: 91.14 $96.46 \%$ ), while for $A$. duodenale it was $88.2 \%$ (95\% CI: 84.64 - 91.76\%). Comparatively, the ERR for $A$. lumbricoides was 96.1\% (95\% CI: 93.96 - 98.24\%) while for A. duodenale it was 91.2\% (95\% CI: 88.07 - 94.33\%). In another report, Keiser and Utzinger ${ }^{[40]}$ estimated ADZ post-treatment cure rates of $88 \%$ (95\% CI, 79\%93\%) for A. lumbricoides and 72\% (95\% CI, 59\%-81\%) for hookworm. Also, in agreement with our results Adugna et al., ${ }^{\left[{ }^{[2]}\right]}$ noted that ADZ had cure and ERR rates of $83.9 \%$ and $96.3 \%$ for $A$. lumbricoides and $84.2 \%$ and 95\% for hookworm infection respectively. Vaz Nery et al., ${ }^{[24]}$ reported that ADZ was highly efficacious against Ascaris spp., with a cure rate of $91.4 \%$ (95\% CI: 85.9$95.2 \%$ ) and infection intensity reduction rate of $95.6 \%$ (95\% CI: 88.3-100\%), but it was less effectual against hook worms with a cure rate of 58.3\% (95\% CI: 51.4$64.9 \%$ ) and infection intensity reduction rate of $88.9 \%$ (95\% CI: 84.0-97.0\%). Also, Soukhathammavong et al., ${ }^{[23]}$ noted that the single dose of ADZ has low therapeutic efficacy on hook worms with a cure rate of $36.0 \%$ and ERRs of $86.7 \%$, while in A. lumbricoides it produces high efficacy with a cure rate of $92.9 \%$ and ERRs of $100 \%$. The author suggested that the apparent lower effect of ADZ on hook worm may be attributed to failure of some children to swallow the tablet correctly, other host factors, co-infections with other helminthes, differences in strains and species susceptibilities, or development of ADZ resistance.

Until now, the standard method for diagnosing STHs infections is microscopic examination for detection of helminth eggs or larva in stool samples. Although this method is easy, simple and of low cost, it suffers from low sensitivity, especially in cases of light infection. The other alternative is PCR assay, which is a highly sensitive technique that can be used for diagnosis of STHs ${ }^{[43]}$. In our study we used conventional multiplex PCR assay that can simultaneously detect $A$. lumbricoides and $A$. duodenale infections with low cost and requiring only a standard thermal cycler. In our study multiplex PCR sensitivity was $100 \%$ for detection of both worms. While, PCR specificity was 96.8\% for $A$. lumbricoides detection, it was $93.8 \%$ for $A$. duodenale. Phuphisut et al., ${ }^{[11]}$ who compared multiplex PCR with microscopic examination of fecal samples detected a sensitivity and specificity of $87 \%$ and $83 \%$, respectively. They accordingly suggested that multiplex PCR assay provides an alternative method for routine diagnosis of STHs infection. Also, Llewellyn et al., ${ }^{[4]}$ reported that multiplex PCR has superior sensitivity for determination of infection with Ascaris and hook worms compared to microscopy, especially in samples exhibiting polyparasitism.

In conclusion, the estimated cure rates and ERR for A. lumbricoides and A. duodenale demonstrate the high efficacy of ADZ against these STHs and its usefulness as a mass chemotherapy agent in Egypt. Furthermore, this 
study demonstrates the practicality of conventional multiplex PCR as a method to measure the therapeutic efficacy of anthelminthic drugs.

Author Contribution: SH Yahia planned the study design, HSF Moawad collected the stool samples and both shared TI Farag and SM Mohammad in parasitological and molecular examination and writing and reviewing the manuscript.

Conflict of interest: There is no conflict of interest. Financial support and sponsorship: Nil.

\section{REFERENCES}

1. Knopp S, Salim N, Schindler T, Karagiannis Voules DA, Rothen J, Lweno 0, et al. Diagnostic accuracy of Kato-Katz, FLOTAC, Baermann, and PCR methods for the detection of light-intensity hookworm and Strongyloides stercoralis infections in Tanzania. Am J Trop Med Hyg 2014; 90(3): 535-545.

2. Yahya RS, Awad SI, Kizilbash N, El-Baz HA, Atia G. Enteric parasites can disturb leptin and adiponectin levels in children. Arch Med Sci 2018; 14 (1): 101106.

3. Katona P, Apte KJ. The interaction between nutrition and infection. Clin Infect Dis 2008; 46: 1582-1588.

4. Cox FEG. History of human parasitology. Clin Microbiol Rev 2002; 15: 595-612.

5. Hotez PJ, Bundy DAP, Kathleen-Beegle K. Helminth infections: soil transmitted helminth infections and schistosomiasis. In: Jamison DT, Breman JG, Measham AR (Eds) Disease control priorities in developing countries. Oxford University Press, New York 2006; 467-482.

6. Crompton DWT. How much human helminthiasis is there in the world? J Parasitol 1999; 85: 397-403.

7. Hotez PJ, Molyneux DH, Fenwick A, Kumaresan J, Sachs SE, Sachs JD, et al. Control of neglected tropical diseases. N Engl J Med 2007; 357(10):1018-1027.

8. WHO. Eliminating soil-transmitted helminthiases as a public health problem in children. Geneva 2012; WHO/HTM/NTD/PCT/2012.4

9. Santos FL, Cerqueira EJ, Soares NM. Comparison of the thick smear and Kato-Katz techniques for diagnosis of intestinal helminth infections. Rev Soc Bras Med Trop 2005; 38:196-198.

10. Verweij JJ, Brienen EA, Ziem J, Yelifari L, Polderman AM, Van Lieshout L. Simultaneous detection and quantification of Ancylostoma duodenale, Necator americanus, and Oesophagostomum bifurcum in fecal samples using multiplex real-time PCR. Am J Trop Med Hyg 2007; 77: 685-690.

11. Phuphisut O, Yoonuan T, Sanguankiat S, Chaisiri K, Maipanich W, Pubampen S, et al. Triplex polymerase chain reaction assay for detection of major soiltransmitted helminthes, Ascaris lumbricoides, Trichuris trichiura, Necator americanus in fecal samples. Southeast Asian J Trop Med Public Health 2014; 45 (2): 267-275.

12. WHO. Schistosomiasis and soil transmitted helminth infections. Geneva 2001; apps.who.int/ iris/bitstream/10665/78794/1/ea54r19.

13. WHO. Preventive chemotherapy in human helminthiasis: coordinated use of anthelminthic drugs in control interventions; a manual for health professionals and programme managers. https://apps.who.int/iris/bitstream/ handle/10665/43545/9241547103_eng

14. Prichard RK, Basáñez MG, Boatin BA, McCarthy JS, Garcia HH, Yang GJ, et al. A research agenda for helminth diseases of humans: intervention for control and elimination. PLoS Negl Trop Dis 2012; 6: e1549.

15. Murray CJL, Vos T, Lozano R, Naghavi M, Flaxman AD, Michaud C, et al. Disability-adjusted life years (DALYs) for 291 diseases and injuries in 21 regions, 1990-2010: a systematic analysis for the global burden of disease study 2010. Lancet 2012; 380: 2197-2223.

16. Hanson C, Weaver A, Zoerhoff KL, Kabore A, Linehan $\mathrm{M}$, Doherty A, et al. Integrated implementation of programs targeting neglected tropical diseases through preventive chemotherapy: identifying best practices to roll out programs at national scale. Am J Trop Med Hyg 2012; 86(3): 508e13.

17. Yap P, Du ZW, Wu FW, Jiang JY, Chen R, Zhou $\mathrm{XN}$, Hattendorf J, et al. Rapid reinfection with soil-transmitted helminths after triple-dose albendazole treatment of school-aged children in Yunnan, People's Republic of China. Am J Trop Med. Hyg 2013; 89(1): 23-31.

18. Furtado LFV, de Paiva Bello ACP, Rabelo E ML. Benzimidazole resistance in helminths: From problem to diagnosis. Acta Trop 2016; 162: 95-102.

19. Clarke NE, Doi SAR, Wangdi K, Chen Y, Clements ACA, Nery SV. Efficacy of anthelminthic drugs and drug combinations against soil-transmitted helminths: a systematic review and network metaanalysis. Clin Infect Dis 2019; 68(1):96-105.

20. Hong ST. Albendazole and praziquantel: review and safety monitoring in Korea. Infect Chemother 2018; 50(1):1-10.

21. Katz N, Chavez A, Pellegrino J. A simple device for quantitative stool thick-smear technique in Schistosomiasis mansoni. Rev Inst Med Trop Sao Paulo 1972; 14: 397-400.

22. Putra DS, Dalimunthe W, Lubis M, Pasaribu S, Lubis C. The efficacy of single dose albendazole for the treatment of ascariasis. Paediatrica Indonesiana 2005; 45(5-6): 118-122.

23. Soukhathammavong PA, Sayasone S, Phongluxa $\mathrm{K}$, Xayaseng V, Utzinger J, et al. Low efficacy of single-dose albendazole and mebendazole against hookworm and effect on concomitant helminth infection in Lao PDR. PLoS Negl Trop Dis 2012; 6(1): e1417. 
24. Vaz Nery S, Qi J, Llewellyn S, Clarke NE, Traub R, Gray DJ, et al. Use of quantitative PCR to assess the efficacy of albendazole against Necator americanus and Ascaris spp. in Manufahi District, Timor-Leste Susana. Parasit Vectors 2018; 11:373.

25. Wiria AE, Prasetyani MA, Hamid F, Wammes LJ, Lell B, Ariawan I, et al. Does treatment of intestinal helminth infections influence malaria? Background and methodology of a longitudinal study of clinical, parasitological and immunological parameters in Nangapanda, Flores, Indonesia. BMC Infect Dis 2010; $10: 77$.

26. Niesters HGM. Clinical virology in real time. J Clin Virol 2002; 25: 3-12.

27. Abd Ella OH, Mohamed EA, Ahmed AM, Omran Kh. E, Ezz Eldin S, Mohamed AE, et al. Ascaris lumbricoides and other gastrointestinal helminthic parasites among Qena inhabitants with special concern to its relation to anemia and eosinophilia. IOSR-JDMS 2015; 14(12): 1-10.

28. Krücken J, Fraundorfer K, Mugisha JC, Sabrina Ramünke S, Sifft KC, Geus D, et al. Reduced efficacy of albendazole against Ascaris lumbricoides in Rwandan schoolchildren. Int J Parasitol Drugs Drug Resist 2017; 7: 262-271.

29. Augusto G, Nalá R, Casmo V, Sabonete A, Mapaco L, Monteiro J. Geographic distribution and prevalence of schistosomiasis and soil-transmitted helminths among school children in Mozambique. Am J Trop Med Hyg 2009; 81:799-803.

30. Smith HM, DeKaminsky RG, Niwas S, Soto RJ, Jolly PE. Prevalence and intensity of infections of Ascaris lumbricoides and Trichuris trichiura and associated sociodemographic variables in four rural Honduran Communities. Mem Inst Oswaldo Cruz 2001; 96(3): 303-314.

31. Hegazy AM, Aminou HA, Badr AM. Prevalence of intestinal parasites and its impact on nutritional status among preschool children living in Damanhur City, El-Behera Governorate, Egypt. Egypt Soc Parasitol 2014; 44(2): 517-524.

32. El-Masry HM, Ahmed YA, Hassan AA, Zaky S, AbdAllah ES, El-Moselhy EA, et al. Prevalence, risk factors and impacts of schistosomal and intestinal parasitic infections among rural school children in Sohag Governorate. Egypt J Hosp Med 2007; 29:616-630.

33. Ibrahium AA. Prevalence and predisposing factors regarding intestinal parasitic infections among rural primary school pupils at Minia Governorate, Egypt. J Pub Hlth Afr 2011; 2: e29.

34. Dyab AK, El-Salahy M,Abdelmoneiem H, Mohammed MF. Prevalence and risk factors associated with intestinal parasitic infection among children in Aswan, Egypt. J Bacteriol Parasitol 2016; 7(5): 59.

35. Esrey SA, Potash JB, Roberts L, Shiff C. Effect of improved water supply and sanitation on ascariasis, diarrhea, hookworm infections and schistosomiasis. Bull WHO 1991; 69(5): 609- 615.

36. Tchuem Tchuente LA. Control of soil-transmitted helminths in sub-Saharan Africa: diagnosis, drug efficacy concerns and challenges. Acta Trop 2011; 120 (1): 4-11.

37. Crompton DW, Nesheim MC. Nutritional impact of intestinal helminthiasis during the human life cycle. Annu Rev Nutr 2002; 22: 35-59.

38. WHO: Prevention and control of schistosomiasis and soil-transmitted helminthiasis: WHO Technical Report Series No. 912, Geneva 2002.

39. Khadka KS, Gurung K, Manoj Sigdel M. Study of intestinal parasitosis among school going children in Pokhara, Nepal. J Hlth Allied Sci 2013; 3(1): 4750.

40. Keiser J, Utzinger J. Efficacy of current drugs against soil-transmitted helminth infections: systematic review and meta-analysis. JAMA 2008; 299: $1937-$ 1948.

41. Verrest L, Dorlo TPC. Lack of clinical pharmacokinetic studies to optimize the treatment of neglected tropical diseases: a systematic review. Clin Pharmacokinet 2017; 56:583-606.

42. Adugna S, Kebede Y, Moges F, Tiruneh M. Efficacy of mebendazole and albendazole for Ascaris lumbricoides and hookworm infections in an area with long time exposure for antihelminthes, Northwest Ethiopia J 2007; 45(3):301-306.

43. Areekul P, Putaporntip C, Pattanawong U, Sitthicharoenchai P, Jongwutiwes S. Trichuris vulpis and T. trichiura infections among schoolchildren of a rural community in northwestern Thailand: the possible role of dogs in disease transmission. Asian Biomed 2010; 4: 49-60.

44. Llewellyn S, Inpankaew T, Nery SV, Gray DJ, Verweij JJ, Clements ACA, et al. Application of a multiplex quantitative PCR to assess prevalence and intensity of intestinal parasite infections in a controlled clinical trial. PLoS Negl Trop Dis 2016; 10(1) e0004380. 